\title{
Article \\ The Effect of Nitrogen Linear Flow on Lubricant Removal and Sintering Densification of Alumix 431D Grade Powder
}

\author{
Jan Kazior ${ }^{1, *}$, Tadeusz Pieczonka ${ }^{2}$ and Mateusz Laska ${ }^{3}$ \\ 1 Department of Materials Engineering, Faculty of Materials Engineering and Physics, \\ Cracow University of Technology, 31-155 Cracow, Poland \\ 2 Department of Physical Metallurgy and Powder Metallurgy, \\ Faculty of Metals Engineering and Industrial Computer Science, AGH University of Science and Technology, \\ 30-059 Cracow, Poland; pieczonk@agh.edu.pl \\ 3 Grupa Azoty S.A., 33-101 Tarnów, Poland; mateusz.laska@grupaazoty.com \\ * Correspondence: jkazior@pk.edu.pl
}

check for updates

Citation: Kazior, J.; Pieczonka, T.; Laska, M. The Effect of Nitrogen Linear Flow on Lubricant Removal and Sintering Densification of Alumix 431D Grade Powder. Metals 2021, 11, 1259. https://doi.org/10.3390/ met11081259

Academic Editors: Andreas

Chrysanthou, Chunfeng $\mathrm{Hu}$ and Elena Gordo

Received: 7 June 2021

Accepted: 6 August 2021

Published: 10 August 2021

Publisher's Note: MDPI stays neutral with regard to jurisdictional claims in published maps and institutional affiliations.

Copyright: (c) 2021 by the authors. Licensee MDPI, Basel, Switzerland. This article is an open access article distributed under the terms and conditions of the Creative Commons Attribution (CC BY) license (https:// creativecommons.org/licenses/by/ $4.0 /)$.

\begin{abstract}
ECKA Granules Alumix 431D commercial grade, press ready, pre-alloyed aluminium-based powder containing 1.5 mass $\%$ of Acrawax $C$ was used to study the effect of nitrogen linear flow on delubrication and sintering densification. In situ dimensional changes were controlled by dilatometry. Microstructural observations of sintered compacts were also performed. The results clearly showed the strong influence of nitrogen linear flow on de-lubrication, and thus on the sintering behaviour of the examined powder. High nitrogen linear flow is required to produce the desired sintered microstructure - characterised by residual porosity. In contrast, at low nitrogen velocity, the lubricant removal is not complete, which in turn significantly impedes densification.
\end{abstract}

Keywords: powder metallurgy; lubricant removal; dilatometry

\section{Introduction}

The main advantage of the sintered structural parts based on aluminium is their low density combined with sufficient mechanical strength. However, the potential of aluminium powder metallurgy is still waiting for development and the wider use of sintered aluminium-based parts is still hindered by some limitations of this technology. In general, the sintered properties are very sensitive to any fluctuations of the processing parameters.

As is typical in powder metallurgy, the addition of a lubricant to aluminium powder reduces friction. Additionally, however, a lubricant is necessary in this case to avoid defects caused by cold welding during compaction, which is not a problem in iron powder metallurgy. Therefore, one of the disadvantages of aluminium powder metallurgy is the need to use a lubricant and, consequently, problems related to its removal. Again, in comparison with iron-based powders, a thorough removal of the lubricant during heating is more crucial for aluminium because of the significantly lower sintering temperature. Moreover, de-lubrication of aluminium-based compacts should be finished prior to the appearance of the first liquid phase, which can take place even below $400{ }^{\circ} \mathrm{C}$ in some systems. Improper lubricant removal or interference of this process with liquid phase formation may deteriorate the sintered properties. In view of this, the lubricant used in aluminium powder metallurgy should be able to decompose easily and to be removed at a low temperature without producing unnecessary compounds. Thus, the amount of lubricant added should be as low as is acceptable.

The conditions of lubricant removal are important in view of their effect on sintering density. It is well known that the gaseous products of lubricant evaporation and/or its degradation tend to form open porosity and generate internal cracks or distortions of the weak compacts at the initial stage of the sintering cycle. A too fast heating rate, e.g., may lead to boiling of the lubricant in the interior of the compact instead of on its surface. This 
can produce swelling and internal cracks, resulting in a loss of direct particle-particle contact. In general, the choice of the lubricant, its amount, lubrication method, and delubrication conditions should be carried out with special care. The search to develop new and better lubrication systems for powder metallurgy is still an open and important question. Generally, one of the main advantages of newly developed lubricants is their metal-free composition, i.e., they are pure organic compounds such as waxes [1].

The most commonly used lubricant for aluminium-based powders is Acrawax $\mathrm{C}$, which is an amide wax - ethylene bis-stearamide (EBS) with the molecular formula $\left(\mathrm{C}_{17} \mathrm{H}_{35} \mathrm{COHN}\right)_{2}$ $\mathrm{C}_{2} \mathrm{H}_{4}$ - containing a small amounts of stearic acid. It is dust-resistant, has a limited effect on lowering the green strength, and a rather small influence on density. Because Acrawax $\mathrm{C}$ is a completely organic material, it has clean burn-off characteristics, in particular, it does not leave any metallic residues after de-lubrication, like metallic soaps do. The drawbacks to the use of Acrawax $C$ are related to the rather poor flowability of the metal powder mixtures that contain it and to a relatively wide de-lubrication range that results from its high molecular weight.

Acrawax $C$ is widely used in iron powder metallurgy. Thus, there are some reports available in the literature dealing with its removal from iron-based compacts [2-4]. Based on these results, it can be stated that there is a general agreement regarding the required temperature to make the de-lubrication process complete, which is about $600{ }^{\circ} \mathrm{C}$. Additionally, Karamchendu et al. [3] pointed out the influence of the gas flow rate on Acrawax C removal and concluded that "dynamic gas flow conditions" around the compacts' surfaces are beneficial for de-lubrication. However, this question was not discussed in detail in the paper.

One of the commercially available aluminium-based powders that has the composition of an aviation alloy is Alumix 431D grade produced by Ecka Granules GmbH. Its chemical composition corresponds to that of the conventional 7075 aluminium alloy. Alumix 431D powder is a mixture of two atomised powders, i.e., that of elemental aluminium and that of aluminium-based master alloy [5-7]. Of course, in this case, the sintering process is responsible for the homogenisation of the alloy. Zinc is very effective in increasing the mechanical properties of the sintered alloy because of the solution-precipitation mechanism, and copper is added to improve the stress corrosion resistance and to assist the ageing process. Magnesium, in turn, has a positive influence on densification during sintering owing to the low melting phase formation and the formation of the spinel $\mathrm{MgAl}_{2} \mathrm{O}_{4}$, which is a product of aluminium oxide disintegration. Generally, it is accepted that successful sintering of aluminium and its alloys requires a liquid phase that penetrates the stable, but spalled, aluminium oxide film covering the powder particles [8]. Additionally, a pure dry nitrogen atmosphere is also necessary for effective sintering of these alloys $[6,9,10]$. In particular, the liquid phase is present during sintering of Alumix 431D compacts [11]. As was demonstrated in our earlier papers [6,7], at least two liquid phases appear in this system, one of them is transient while the other is persistent. The latter liquid leads the process to be known as supersolidus sintering.

It is worth noting that the function of sintering atmosphere in aluminium powder metallurgy does not help in the reduction of oxide films, which is typical for sintering of other metals, including iron. Thus, besides chemical and physical interactions with aluminium [12], the removal of the lubricant's vapour and volatile products of its decomposition seems to be the main role of the flowing nitrogen sintering atmosphere in the manufacturing of sintered parts made of aluminium alloys. Yuan et al. demonstrated [13] the influence of the nitrogen gas flow pattern on the sintering of a 7xxx aluminium alloy produced from elemental powders with compacts' distortion. In particular, they analysed the effect of the sample position in the furnace on its distortion. Generally, they documented that the $\mathrm{Al}-\mathrm{Zn}-\mathrm{Mg}-\mathrm{Cu}$ system is very sensitive to the fluctuations of local gas flow conditions near the sample surfaces, which results in different deformations, pore distribution, and even chemical composition in different regions of the compact. However, they 
assumed that the de-lubrication step at $360^{\circ} \mathrm{C}$ for $40 \mathrm{~min}$ is sufficient for complete Acrawax $\mathrm{C}$ removal, and they did not analyse the role of nitrogen flow on de-lubrication either.

In contrast to the iron powder metallurgy, the de-lubrication process of aluminiumbased compacts is poorly described. Furthermore, to the best knowledge of the authors, there are no data presenting the influence of the linear flow of the sintering atmosphere on the sintering behaviour and thus on the sintering properties of aluminium-based compacts. Therefore, the main purpose of this work was to show the effect of the nitrogen linear flow on lubricant removal and densification taking place during sintering of compacts made of Alumix 431D grade press ready powder mixture containing Acrawax C.

\section{Materials and Methods}

Alumix 431D commercial grade aluminium-based powder [5] and a lubricant-the synthetic wax known as Acrawax $C$ in the form of a powder were used in this study. The press ready mixture containing 1.5 mass\% of Acrawax C was supplied by ECKA/Granules (Velden, Germany). SEM images of Alumix 431D powder are shown in Figure 1. The raw powder mixture comprised air-atomised aluminium powder with alloying additions in the form of a master alloy powder (Figure 2). The composition of the Aluminix 431D powder is shown in Table 1, and is very similar to wrought 7075 alloys. Energy dispersive spectrscopy analysis of both types of powder particles confirmed the metallographic observations (Table 2).

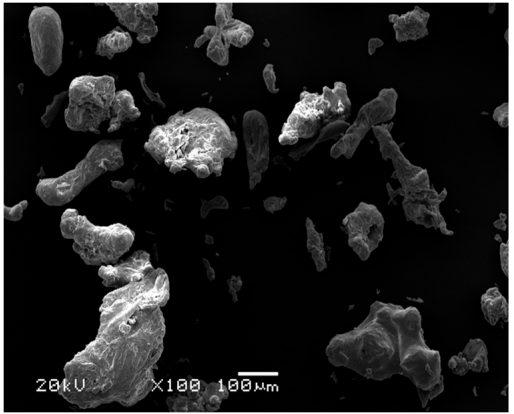

(a)

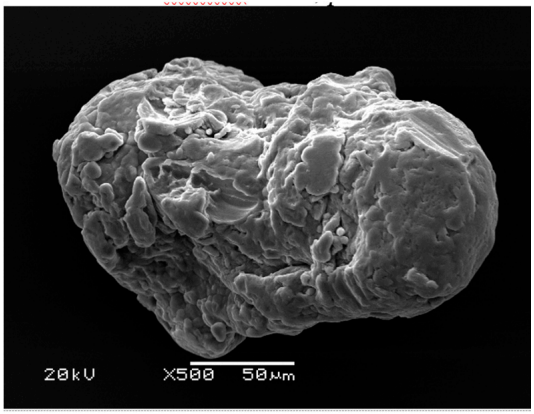

(b)

Figure 1. SEM images of Alumix 431D powder (a) magnification $\times 100$ (b) magnification $\times 500$.

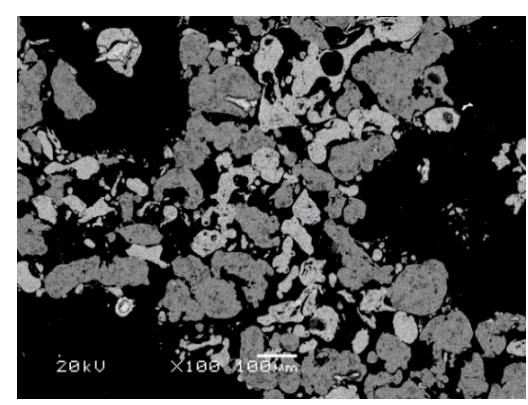

(a)

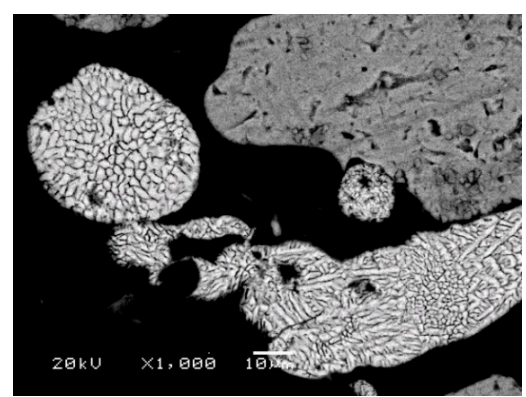

(b)

Figure 2. Backscattered electrons mode SEM image of Alumix 431D powder mixture: cross sections of air-atomised aluminium (monolitic grey) and master alloy (light) particle are visible (a) general image, (b) detailed image showing eutectic type mictrostructure of master alloy.

Table 1. Composition of Alumix 431D grade powder without lubricant produced by ECKA Granules $\mathrm{GmbH}[5]$.

\begin{tabular}{ccccccc}
\hline Zn & $\mathbf{C u}$ & Mg & Si & Fe & Sn & Al \\
\hline 5.8 & 1.6 & 2.6 & Mass $\%$ & & \\
\hline
\end{tabular}


Table 2. Energy dispersive analysis of $\mathrm{Al}$ and master alloy particles/mass $\%$.

\begin{tabular}{ccccccc}
\hline Element & $\mathbf{M g}$ & $\mathbf{A l}$ & $\mathbf{C u}$ & $\mathbf{Z n}$ & $\mathbf{S n}$ & Total \\
\hline Line & $\mathrm{Ka}$ & $\mathrm{Ka}$ & $\mathrm{Ka}$ & $\mathrm{Ka}$ & $\mathrm{La}$ & \\
Aluminium particle & 0.425 & 99.082 & 0.214 & 0.271 & 0.008 & 100.00 \\
Master alloy particle & 4.188 & 83.706 & 2.554 & 9.198 & 0.335 & 100.00 \\
\hline
\end{tabular}

The powder was designed to show good compressibility, high sinterability, providing near full sintered density and high strength sintered products.

Lubricant Acrawax C is composed of ethylene bis-stearamide-EBS-(about 98\%) and stearic acid (about 2\%). Some principal characteristics of the lubricant are shown in Table 3.

Table 3. Characteristics of Acrawax C [1,14].

\begin{tabular}{|c|c|c|c|c|c|c|}
\hline $\begin{array}{c}\text { Physical } \\
\text { State at } \\
\text { RT }\end{array}$ & $\begin{array}{c}\text { Density } \\
\mathrm{g} / \mathrm{cm}^{3}\end{array}$ & $\begin{array}{l}\text { Melting } \\
\text { Point, }{ }^{\circ} \mathrm{C}\end{array}$ & $\begin{array}{l}\text { Boiling } \\
\text { Point, }{ }^{\circ} \mathrm{C}\end{array}$ & $\begin{array}{c}\text { Flash Point, } \\
{ }^{\circ} \mathrm{C}\end{array}$ & $\begin{array}{l}\text { Decoposition } \\
\text { Temperature, } \\
{ }^{\circ} \mathrm{C}\end{array}$ & Residue \\
\hline Powder & $0.97-1.068$ & $135-146$ & 260 & 285 & 260 & None \\
\hline
\end{tabular}

Helium pycnometer Pycnomatic ATC was used to establish the theoretical density of the powder used in the experiments. Additionally, the pycnometric density of the fully dense alloy made of Alumix 431D powder was also measured. The results are shown in Table 4. Some other principal properties of Alumix 431D powder containing 1.5 mass $\%$ (which is roughly $4 \%$ by volume) of Acrawax $C$ were assessed under standard conditions. The results are listed in Table 5.

Table 4. Pycnometer densities of Alumix 431D powder and the fully dense alloy of the same composition.

\begin{tabular}{cc}
\hline Material & Pycnometr Density $\mathbf{g} / \mathbf{c m}^{\mathbf{3}}$ \\
\hline Press-ready Alumix 431D powder & 2.69 \\
Alumix 431D powder without lubricant & 2.75 \\
Fully dense alloy (without lubricant) & 2.76 \\
\hline
\end{tabular}

Table 5. The effect of Acrawax $C$ admixed with Alumix 431D powder on the mixture's properties and on its compaction behaviour.

\begin{tabular}{|c|c|c|c|c|c|}
\hline $\begin{array}{c}\text { Flowability }{ }^{1} \\
\text { s/50 g }\end{array}$ & $\begin{array}{c}\text { Apparent } \\
\text { Density } \\
\mathrm{g} / \mathrm{cm}^{3}\end{array}$ & $\begin{array}{c}\text { Green Density }{ }^{2} \\
\mathrm{~g} / \mathrm{cm}^{3}\end{array}$ & $\begin{array}{c}\text { Ejection Force } \\
\text { KN }\end{array}$ & $\underset{\%}{\text { Spring Back }}$ & $\begin{array}{l}\text { Green } \\
\text { Strength }^{3} \\
\mathrm{MPa}^{3}\end{array}$ \\
\hline 19.38 & 1.09 & 2.55 & 9.13 & 1.08 & 0.83 \\
\hline
\end{tabular}

${ }^{1}$ diameter of cone's hole $-5 \mathrm{~mm}^{2}$ bend strength bar $10 \times 10 \times 30 \mathrm{~mm}^{3}$, compaction pressure $-620 \mathrm{MPa},{ }^{3}$ three point bending method.

The rectangular green compacts $\left(15 \times 4 \times 4 \mathrm{~mm}^{3}\right)$, suitable for dilatometry experiments, were prepared by uniaxial pressing at a compaction pressure of $400 \mathrm{MPa}$. The green density was measured using the geometrical method, i.e., from weight and dimensional measurements. It was calculated to be about $87 \%$ of the theoretical density.

Sintering was performed in a Netzsch 402C dilatometer (Netzsch Gerätebau GmbH, Selb, Germany). The samples were placed with their length oriented parallel to the direction of nitrogen flow (Figure 3).

Sintering cycle consisted of heating at $10{ }^{\circ} \mathrm{C} / \mathrm{min}$. directly to the isothermal sintering temperature of $600^{\circ} \mathrm{C}$, at which the compacts were held for $60 \mathrm{~min}$, and cooled at $20^{\circ} \mathrm{C} / \mathrm{min}$. to room temperature. Nitrogen of 5.0 purity was used as the gas atmosphere. The gas linear flow was assumed as a linear speed of the gas moving within the dilatometer's pipe taking into account the available cross section for the free gas flow. Different gas linear flows were analysed to determine at which value of gas flow, the complete removal of the lubricant and the densification of the powder can be achieved, as well as to determine the gas linear 
flow which does not result in the removal of the lubricant and the densification of the sinter. Therfore, the linear flow $(v)$ estimated in this way were fixed for 6 and $120 \mathrm{~cm} / \mathrm{min}$. Assuming that the nitrogen gas is incompressible and the its thermophysical properties at $600{ }^{\circ} \mathrm{C}$ and at atmospheric pressure are characterised by density $\rho=0.3857 \mathrm{~kg} / \mathrm{m}^{3}$ and dynamic viscosity $v=38.02 \times 10^{-6} \mathrm{~Pa} \cdot \mathrm{s}$ [14-16], it can be stated that the nitrogen flow for both linear flows was laminar, since the calculated Reynolds numbers in a tube furnace $\left(R_{\mathrm{e}}=\rho \cdot v \cdot D / v\right)$ are close to 0 for a flow rate of $6 \mathrm{~cm} / \mathrm{min}$. and to 2 for $120 \mathrm{~cm} / \mathrm{min}$.
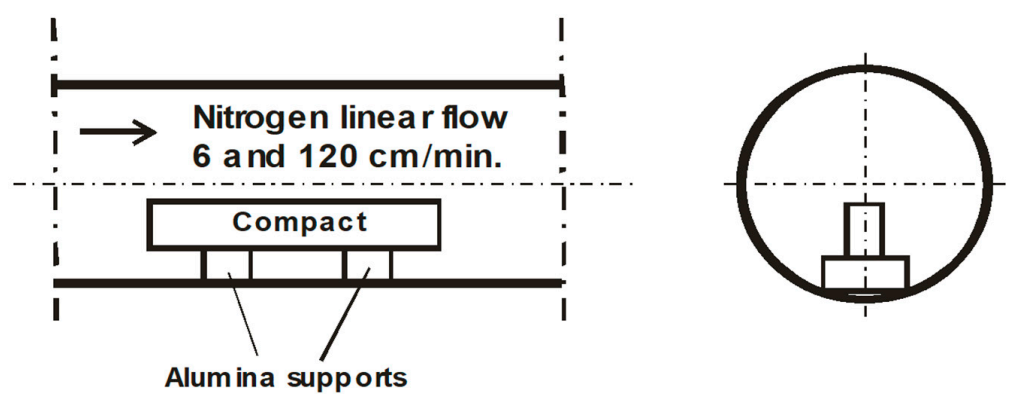

Figure 3. Schematic representation of the compacts' location in the dilatometer.

For microstructural investigations, cross sections parallel to the compaction direction were prepared. Raw powders and cross-sections, which were made parallel to the pressing direction, were observed on green and sintered compacts by a JEOL JSM 5510LV (JEOL Ltd. Tokyo, Japan) equipped with energy dispersive spectroscopy to IXRF 2000 analyser (IXRF, Inc., Austin, TX, USA) and by an optical Leica microscope (Leica Microsystem, Wetzlar, Germany).

\section{Results}

Figure 4 shows the relationship of relative density vs. atmosphere linear flow. Based on previously published our earlier research [6,7], to determine the effect of different manufacturing process parameters on the integrity of the manufactured components, it was determined that, nitrogen flow seems to be a crucial parameter determining the densification behaviour of compacts during sintering. Only high gas linear flow 120 [cm/min] supports shrinkage and enables the production of sintered compacts with residual porosity. The same compacts swell when sintered at the same temperature but under lower gas flow conditions than $120[\mathrm{~cm} / \mathrm{min}]$.

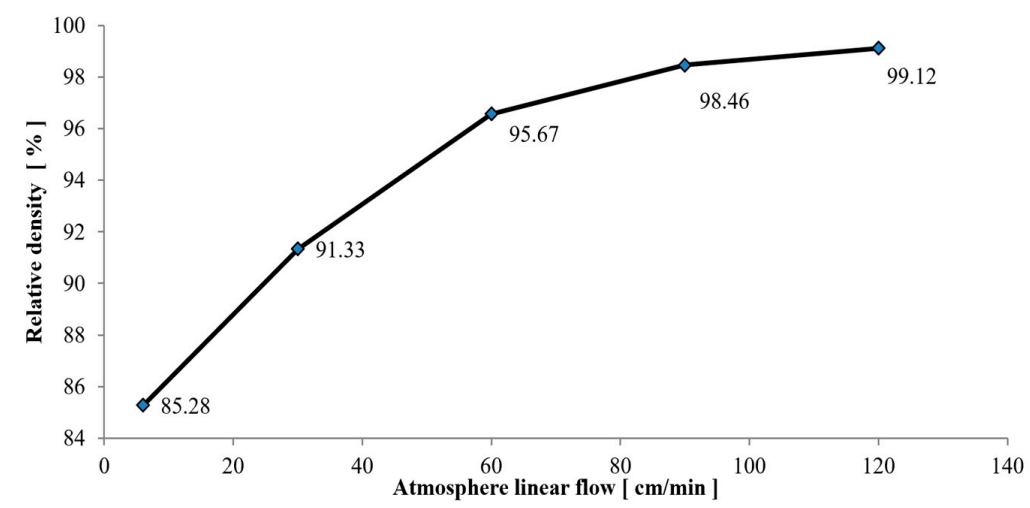

Figure 4. Relative density (\%) of sintered Alumix 431D vs atmosphere linear flow ( $\mathrm{cm} / \mathrm{min})$.

Dilatometry curves shown in Figure 5 demonstrate the dimensional behaviour of compacts made of Alumix 431D powder that had undergone the same thermal cycle during sintering. The only difference in sintering conditions was the linear flow of nitrogen. To interpret the kinetic of dimensional changes, the derivative curves (dimensional change rate curves) were also constructed (Figure 6). 


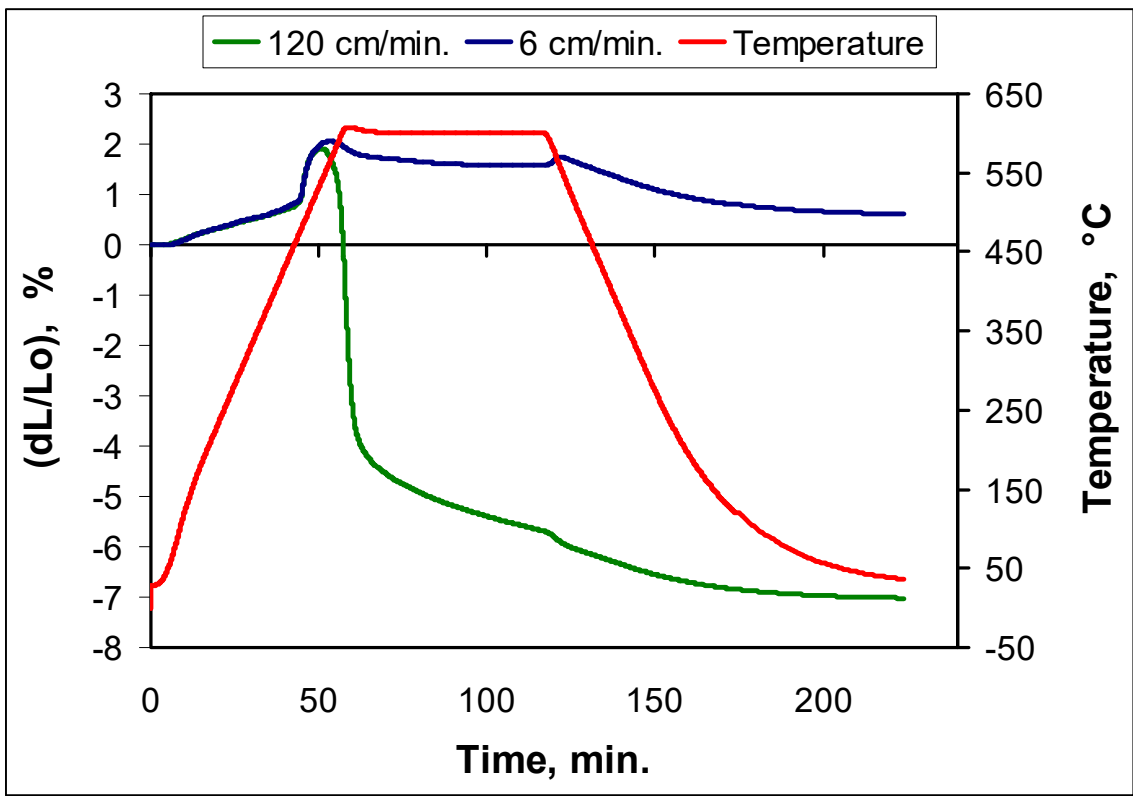

Figure 5. Dilatometry curves for sintering of Alumix 431D compacts containing 1.5 mass $\%$ of Acrawax $\mathrm{C}$ at different nitrogen linear flows.

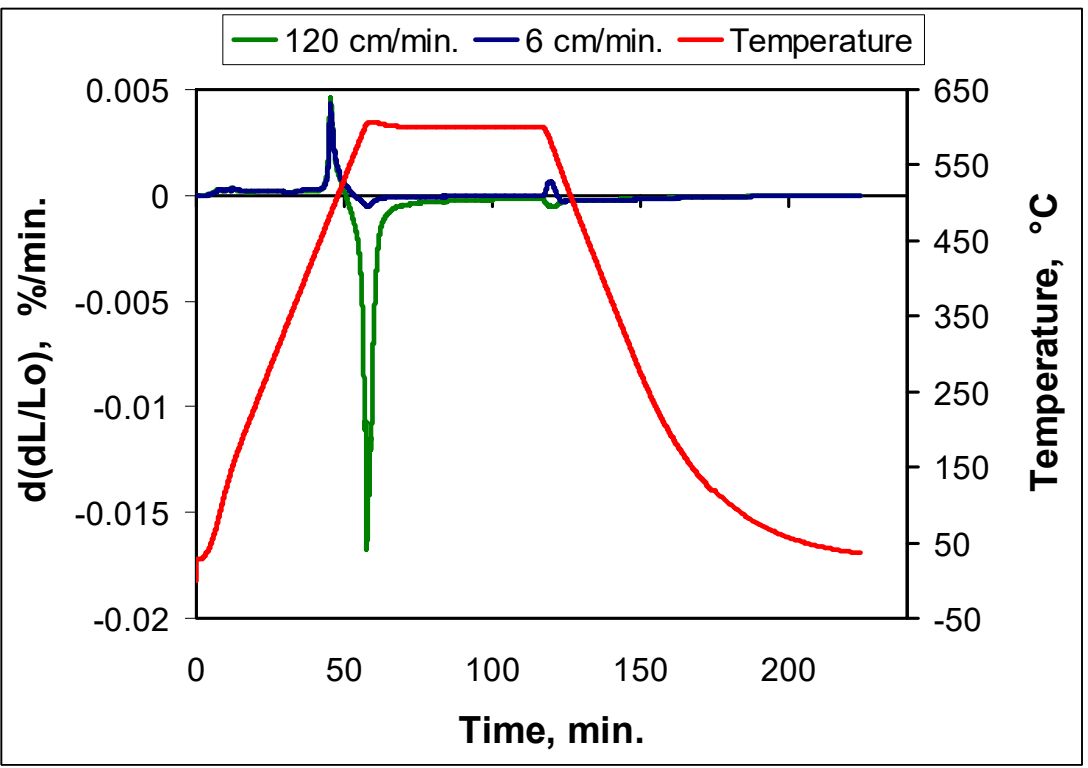

Figure 6. Dimensional change rate curves for sintering of Alumix 431D compacts containing 1.5 mass \% of Acrawax C for different nitrogen linear flows.

Figure 7 demonstrates the abnormal dimensional behaviour of the material sintered by slow gas flow at the beginning of the cooling period. Typically, the transition from the isothermal to cooling steps is accompanied by a sudden, although small, enhanced shrinkage of the sintered material, which is also the case for Alumix 431D compacts sintered at the high nitrogen linear flow. In contrast, at the same point in the thermal run, some sudden swelling appears in compacts sintered at the low gas velocity. 


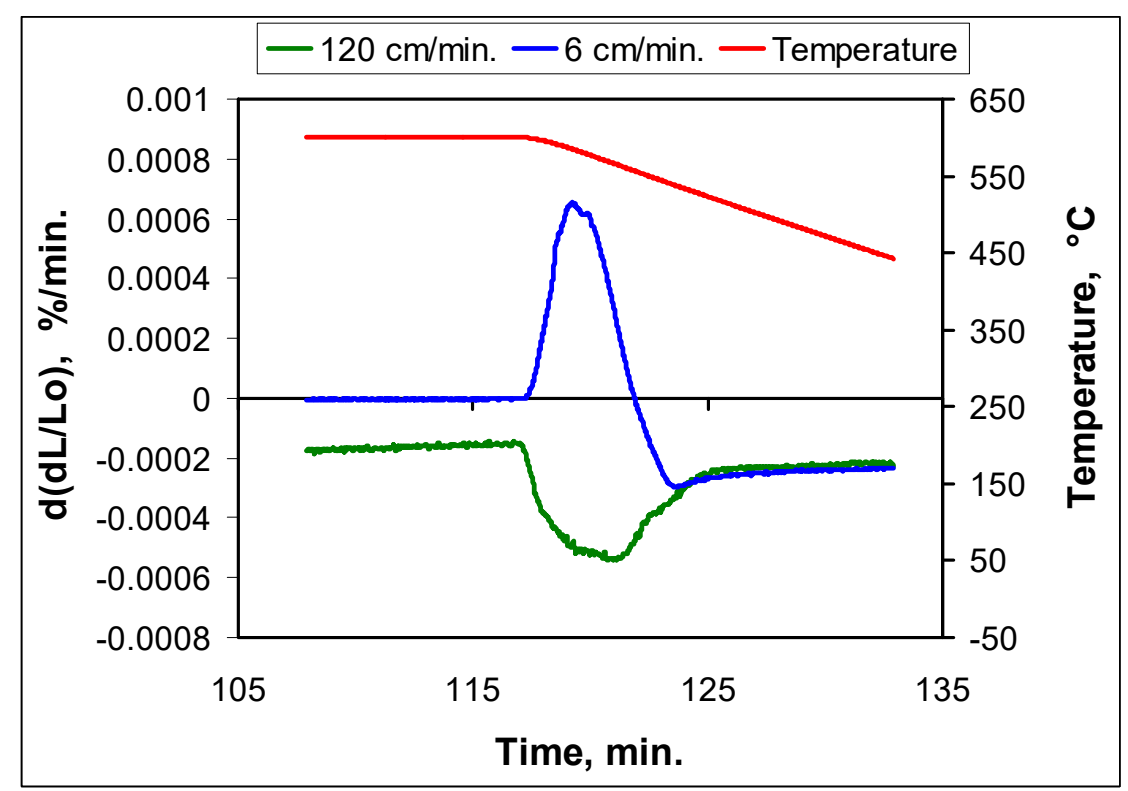

Figure 7. Detailed (from Figure 5) dimensional change rate curves related to the beginning of the cooling stage after the isothermal sintering step for different nitrogen linear flows.

\section{Discussion}

The effect of gas velocity on dimensional changes is evident (Figure 5) where, at a high linear flow, a significant shrinkage is produced, while a low linear flow leads to a final swelling. This finding was also confirmed by additional tests carried out on TG, DTG, and QMS, as described in our previous study [7], where the effect of gas linear flow on the removal of the lubricant was analysed.

It is worth emphasising, that the QMS results unambiguously document that the primary Acrawax $\mathrm{C}$ decomposition products are volatile. During heating, the large organic molecules break apart and degrade into lower mass products, such as simple $\mathrm{H}_{2} \mathrm{O}$ or $\mathrm{CO}_{2}$ compounds, as well as into low mass hydrocarbons. No chemical interactions between nitrogen molecules and the released gases were recorded. Thus, in view of de-lubrication, nitrogen acts merely as a transport agent of volatile degradation products. If the transport is insufficient, involatile carbonaceous residues are formed [7].

Initially, during the first heating period, only thermal expansion occurs. It has to be noted that there are no visible dimensional effects related to the de-lubrication. Thus, it can be stated that, for the chosen heating rate, the network of open pores was sufficient to allow free transport of melted and evaporated lubricant and its gaseous decomposition products from the interior to the surface of the compacts. Independently of the gas linear flow, a transient swelling starting at about $460^{\circ} \mathrm{C}$ is observed, which is attributed to the transient liquid phase flinear formation [6], simply by the melting of the master alloy particles. Meanwhile, according to GoodFellow, for the solid alloy type 7075, the lowest melting point is $477^{\circ} \mathrm{C}$. The amount of this swelling is partly related to the difference in densities of solid and liquid master alloys, but mainly attributed to the distribution of the transient liquid on aluminium particles. The temperature of $450{ }^{\circ} \mathrm{C}$, at which the swelling proceeds, corresponds to the temperature of amorphous $\rightarrow \gamma$-crystalline transformation in alumina [12], leading to the disruption of this oxide layer. Owing to the contact of the liquid alloy wetting the revealed aluminium, further oxide layer disruption may occur by alumina-aluminium interface penetration [8]. Thus, the principal mechanisms of fracture and debonding behaviour of the alumina layer taking place during aluminium sintering in a nitrogen atmosphere are as follows: thermal expansion mismatch, volume changes, liquid alloy formation and interfacial penetration, and erosion through formation of volatile species $[7,8,12]$. As a result of the significant increase of the liquid alloy-aluminium interface, an enhanced dissolution of aluminium in the liquid develops, which in turn 
causes the disappearance of the liquid in a short time. This moment corresponds to the end of swelling. It is seen in Figure 5 that the transient swelling reaches its maximum at $\sim 540{ }^{\circ} \mathrm{C}$ for compacts sintered at the higher gas linear flow, and at $\sim 560{ }^{\circ} \mathrm{C}$ for those sintered at the lower gas linear flow. Then, a persistent liquid alloy appears [6], which makes the transition to shrinkage possible. Now, the effect of the atmosphere velocity becomes more evident. The same amount of swelling and the same rate of swelling (Figure 6) during heating suggest that the composition and the amount of the transient liquid phase are not influenced by the gas flow. However, it seems that this is not true for the persistent liquid. It is known from liquid phase sintering theory that, to promote densification, the liquid should be able to spread throughout the surface of the contacting solid phase, which requires good wettability in the system. As Figure 5 clearly shows, the high linear flow of nitrogen is necessary to assure the beneficial conditions producing shrinkage. In contrast, incomplete removal of lubricant's decomposition products from the compacts sintered at the low gas linear flow dramatically deteriorates densification. This is a consequence of the stable de-lubrication products that remain within the compact as a layer on pores' surfaces, significantly reducing wettability and, in this way, also particle rearrangement.

Dimensional change rate curves in Figure 6 confirm the same behaviour of the transient liquid for both nitrogen flows. In contrast, the effect of the persistent liquid on the densification rate is strongly dependent on nitrogen velocity: particle rearrangement is hardly evident at low linear flow, while that mechanism of shrinkage seems to be highly developed when sintering is performed with fast flowing nitrogen. Of course, high densification is accompanied by the desired microstructure formation characterised by only uniformly distributed small residual pores, which is documented in Figure 8. In contrast, sintering at a low nitrogen linear flow produces poorly sintered compacts (Figure 9), with a high densification area only within the central part, while exterior regions of about $100 \mu \mathrm{m}$ in depth are poorly sintered.

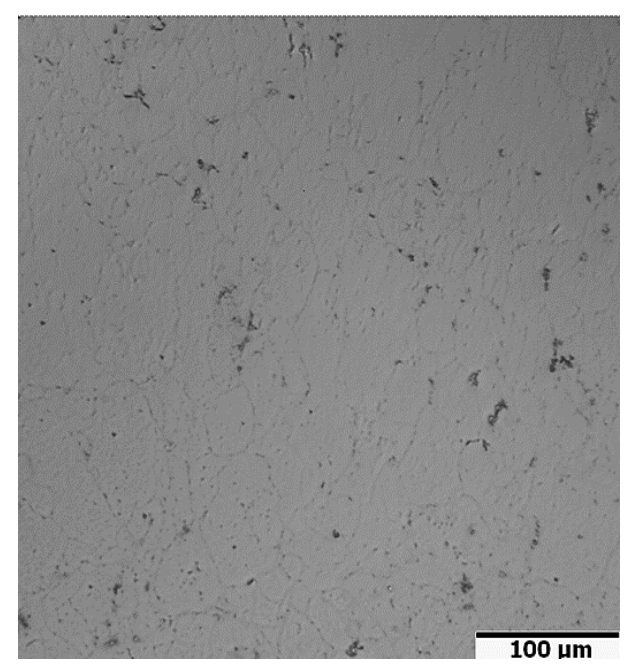

Figure 8. Typical microstructure of the compacts made of Alumix 431D powder containing 1.5 mass $\%$ of Acrawax C sintered at a nitrogen linear flow of $120 \mathrm{~cm} / \mathrm{min}$.

Furthermore, the influence of the different nitrogen linear flow on mechanical properties of investigated materials is documented in Figure 10. The experimental results also confirm the well-known fact in powder metallurgy that an increase in densification contributes to an improvement in mechanical properties. In any case, the effect of nitrogen linear flow is more pronounced.

Aditionally, backscattered SEM observations of as sintered compacts were also performerd, and some images were published in our previous paper [6]. It was found that some decoration of grain boundaries by the precipitated phases and within the matrix grains was found. Thus, it can be assumed that nitrogen also promotes the precipitation of 
dispersion phases. It is well known that 7xxx series alloys are suitable for strengthening through precipitation mechanisms [11,17].

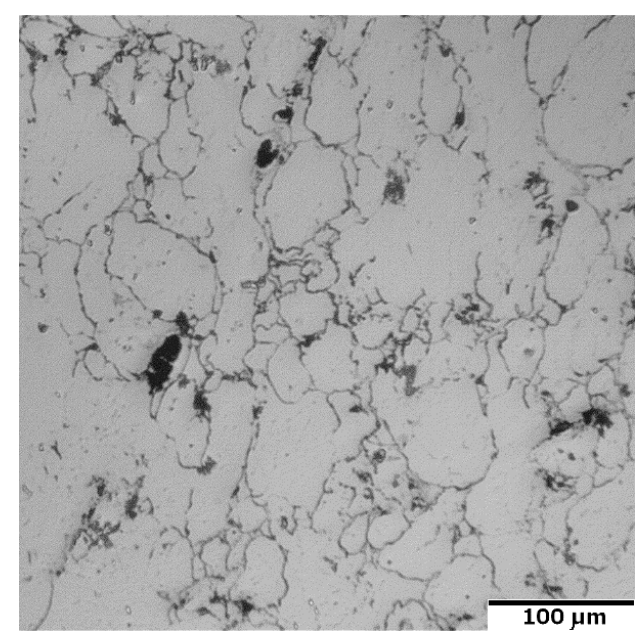

Figure 9. Typical microstructure of poorly sintered compacts made of Alumix 431D powder containing 1.5 mass $\%$ of Acrawax $C$ sintered at a nitrogen linear flow of $6 \mathrm{~cm} / \mathrm{min}$.

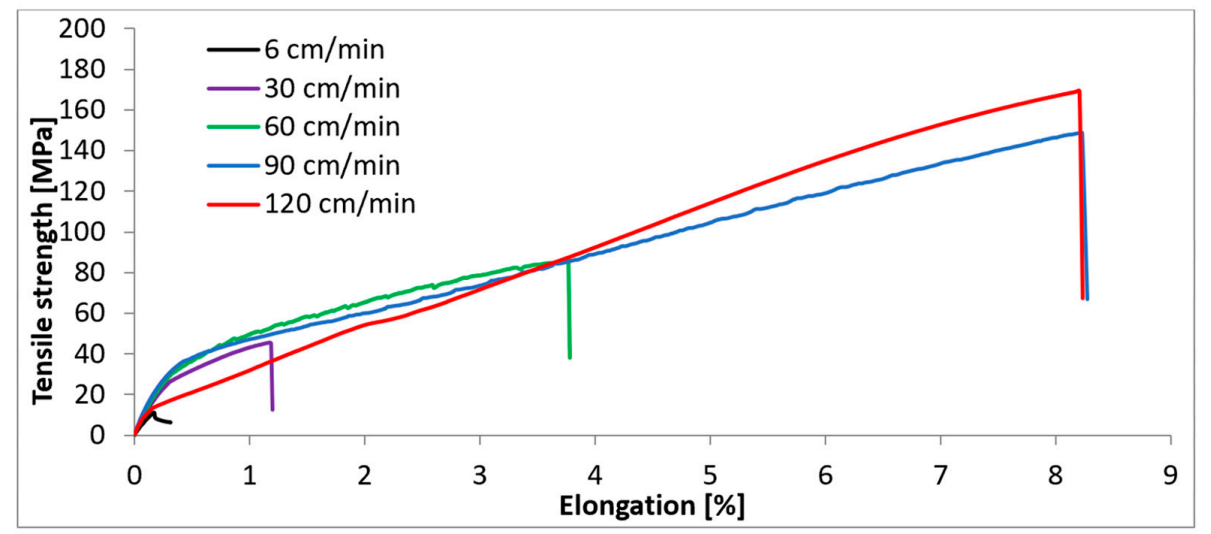

Figure 10. Tensile test curves registered to failure for specimens sintering at $600{ }^{\circ} \mathrm{C}$ temperature under different gas linear flows.

The phases present in the sintered compact produced were identified by X-ray diffraction. Among a large number of possible intermetallic phases that can be formed between elements present in the experimental alloy, $\mathrm{MgZn}_{2}$ was detected unambiguously. Spinel $\mathrm{MgAl}_{2} \mathrm{O}_{4}$ and a phase $\mathrm{Al}_{5} \mathrm{OMg}_{48} \mathrm{Cu}_{2}$ were also identified. There are also some indications that other phases, like $\mathrm{Al}_{2} \mathrm{Cu}, \mathrm{AlCu}_{3}$, or $\mathrm{AlMg}$, are also present [6].

The abnormal swelling behaviour in Figure 6 was not analysed in the present work. It was already shown [6] that, at the beginning of the cooling period, the persistent liquid phase solidifies. Thus, swelling may probably result from the limited homogenisation of the material taking place during sintering at a low nitrogen linear flow. Homogeneous alloy formation is hindered in this case by the involatile carbonaceous residues present within the compacts, which reduce the amount of persistent liquid and, with a lack of wettability, also impede its distribution. Thus, at this stage of investigation, we can assume that swelling is an intrinsic property of the liquid phase during its solidification.

\section{Conclusions}

Relatively low sintering temperature of Alumix 431D compacts requires the use of lubricants that can be almost fully removed during heating occurring before isothermal sintering. Acrawax $\mathrm{C}$ is recognized as the best lubricant fulfilling this requirement. The current experiments showed that the de-lubrication behaviour and lubricant removal strongly 
depend on the linear flow of the sintering atmosphere. At insufficient nitrogen velocity, dewaxing is not complete, which significantly impedes or even eliminates the densification. In contrast, fast flowing nitrogen effectively removes the lubricant's decomposition products away from the pore network and de-lubrication zone. Thus, a significant shrinkage is produced and the sintered compacts are nearly fully dense.

\section{Patents}

Patents resulting from the work are reported in this manuscript. Patent PL Nr 222107-Sposób wytwarzania spiekanych elemntów o osnowie aluminium cechujących się resztkowa porowatościa (Method of producing sintered aluminium matrix components with residual porosity).

Author Contributions: Conceptualization, J.K and T.P.; methodology, M.L.; software, M.L.; validation, J.K., T.P. and M.L.; formal analysis, T.P.; investigation, M.L.; resources, T.P.; data curation, J.K.; writing—original draft preparation, T.P.; writing—review and editing, J.K.; visualization, T.P.; supervision, J.K.; project administration, J.K.; funding acquisition, J.K. All authors have read and agreed to the published version of the manuscript.

Funding: This research was funded by POIG, grant number 01.01.02-00-015/09-00.

Data Availability Statement: Data presented in this article are available at request from the corresponding author.

Conflicts of Interest: The authors declare no conflict of interest.

\section{References}

1. Lonza Inc. Leaflet "ACRAWAX C". 2010. Available online: www.lonza.com (accessed on 1 May 2017).

2. Baum, M.M.; Becker, R.M.; Lappas, A.M.; Moss, J.A.; Apellian, D.; Saha, D.; Kapinus, V.A. Lubricant pyrolysis during sintering of PM compacts. Metall. Mater. Trans. B 2004, 35B, 381-392. [CrossRef]

3. Karamchedu, S.; Hryha, E.; Nyborg, L. Influence of process parameters on the delubrication of PM steels. Powder Metall. Prog. 2011, 11, 90-96.

4. Hryha, E.; Nyborg, L. Process control system for delubrication of PM steels. Acta Metall. Slovaca 2012, 18, 60-68.

5. Ecka Granules-Metal Powder Technologies. ECKA ALUMIX ${ }^{\circledR}$ 431, Brochure: Press-Ready Mix for Aluminum Sintered Parts; Ecka: Granules, Germany, 2010.

6. Pieczonka, T.; Kazior, J.; Szewczyk-Nykiel, A.; Hebda, M.; Nykiel, M. The effect of the atmosphere on sintering of Alumix 431D powder. Powder Metall. 2012, 55, 354-360. [CrossRef]

7. Pieczonka, T.; Kazior, J.; Laska, M. The effect of nitrogen flow rate on Acrawax decomposition and its removal during sintering of Alumix 431D grade powder. Powder Metall. 2018, 61, 149-156. [CrossRef]

8. Kehl, W.; Fischmeister, H.F. Liquid phase sintering of Al-Cu compacts. Powder Metall. 1980, 23, 113-119. [CrossRef]

9. Schaffer, G.B.; Hall, B.J. The influence of the atmosphere on the sintering of aluminium. Metall. Mater. Trans. A 2002, 33A, 3279-3284. [CrossRef]

10. Pieczonka, T.; Schubert, T.; Baunack, S.; Kieback, B. Dimensional Behaviour of Aluminium Sintered in Different Atmospheres. Mater. Sci. Eng. A 2008, 478, 251-256. [CrossRef]

11. LaDelpha, A.D.P.; Neubing, H.; Bishop, D.P. Metallurgical assessment of an emerging Al-Zn-Mg-Cu P/M alloy. Mater. Sci. Eng. A 2009, 520, 105-113. [CrossRef]

12. Pieczonka, T. Disruption of an Alumina Layer During Sintering of Aluminium in Nitrogen. Arch. Metall. Mater. 2017, 62, 987-992. [CrossRef]

13. Yuan, X.N.; Huo, S.H.; Schaffer, G.B.; Qian, M. Distortion in a 7xxx Aluminum Alloy during Liquid Phase Sintering. Mater. Sci. Eng. A 2014, 45A, 1010-1018. [CrossRef]

14. Open Chemistry Database, Compound 110-30-5. Available online: http://pubchem.ncbi.nlm.nih.gov/compound/8044\#section= Experimental-Properties (accessed on 1 May 2017).

15. Dortmund Data Bank, Dynamic Viscosity of Nitrogen. Available online: http://www.ddbst.com/en/EED/PCP/VIS_C1056.php (accessed on 1 May 2017).

16. Peace Software. Available online: http:/ /www.peacesoftware.de/einigewerte/stickstoff_e.html (accessed on 1 May 2017).

17. Huie, H.; Xinun, W. Effect of Heat Treatment on the In-Plane Anisotropy of As-Rolled 7050 Aluminum Alloy. Metals 2016, 6, 79. [CrossRef] 